This document is the accepted manuscript version of the following article:

Gallego, J. M., Czaderski, C., Breveglieri, M., \& Michels, J. (2018). Fatigue behaviour at elevated temperature of RC slabs strengthened with EB CFRP strips. Composites Part B: Engineering, 141, 37-49. http://doi.org/10.1016/j.compositesb.2017.12.026

This manuscript version is made available under the CC-BY-NC-ND 4.0

license http://creativecommons.org/licenses/by-nc-nd/4.0/

\title{
Fatigue behaviour at elevated temperature of RC slabs strengthened with EB CFRP strips
}

\author{
Juan Manuel Gallego ${ }^{1,2}$, Christoph Czaderski ${ }^{1 *}$, Matteo Breveglieri ${ }^{1}$, Julien Michels ${ }^{1,3}$ \\ ${ }^{1}$ Swiss Federal Laboratories for Materials Science and Technology (Empa), Dübendorf, Switzerland \\ ${ }^{2}$ WMM Ingenieure AG, Basel, Switzerland \\ ${ }^{3}$ re-fer AG, Brunnen, Switzerland
}

\begin{abstract}
Reinforced concrete (RC) structures such as concrete box-girder highway bridges may suffer fatigue damage due to cyclic loads. Externally bonded (EB) carbon fibre reinforced polymer (CFRP) strips can be used to increase the fatigue (and static) load bearing capacity of such elements and to increase the service life of the elements. The EB CFRP strips under the asphalt layer can reach elevated temperatures of up to $50^{\circ} \mathrm{C}$ during summer when the asphalt is directly exposed to solar radiation. Therefore, in this study, the fatigue behaviour at an elevated temperature of RC slabs strengthened with EB CFRP strips is evaluated. The focus is on the strengthening of lateral cantilevers of deck slabs of concrete box-girder highway bridges.

The fatigue behaviour of RC elements is a complex phenomenon that is influenced by many parameters such as the maximum load, stress oscillation level on the longitudinal steel reinforcement, shear span-to-depth ratio, and quality of concrete. This phenomenon becomes even more complicated when elevated temperatures are considered. Majority of the existing experimental works on fatigue behaviour of EB-strengthened RC structures showed that the typical fatigue failure at room temperature is caused by fatigue failure of the longitudinal steel reinforcement followed by strip debonding. In this study, it was investigated if a different type of failure can be observed at elevated temperatures owing to the changes in epoxy properties.
\end{abstract}

Keywords: Externally bonded CFRP strips; box-girder bridges; RC slabs; fatigue; elevated temperature; durability.

\section{Introduction}

Many reinforced concrete (RC) structures, such as the lateral cantilevers of deck slabs of concrete boxgirder highway bridges, wind towers, or offshore structures, may suffer fatigue damage due to cyclic loads. Externally bonded (EB) carbon fibre reinforced polymer (CFRP) strips are sometimes used to increase the load bearing capacity of such elements subjected to fatigue loads or to increase the service life of the elements.

Experimental studies demonstrated that the application of EB CFRP strips reduces the tensile stresses in the steel bars, and therefore, also increases their fatigue life [1,2]. These investigations have verified that at room temperature, the typical fatigue failure mode is due to fracture of the longitudinal steel reinforcement, followed by delamination of the EB CFRP strip. The delamination usually occurs within few cycles after the

*Corresponding author; Tel.: +41 5876542 16, E-mail address: christoph.czaderski@empa.ch, Address: Empa, Swiss Federal Laboratories for Materials Science and Technology, Structural Engineering Research Laboratory, Überlandstrasse 129, 8600 Dübendorf, Switzerland. 
fatigue failure of the first steel reinforcing bar. Thus, most researchers recommend that the criteria for fatigue design of strengthened beams with EB CFRP strips should be based on the fatigue strength of the longitudinal steel reinforcement $[1,2]$.

Small-scale beams strengthened with EB CFRP strips were tested under four-point bending fatigue by Gheorghiu et al. [3]. After 2 million load cycles, a significant increase in the mid-span deflection approximately equal to $40 \%$ of the initial value was measured owing to stiffness degradation during load cycling. Fatigue tests on strengthened RC beams performed by Ferrier et al. [4], demonstrated that concrete and steel strength limit the loading to be applied during fatigue. This limitation is not due to the FRP tensile strength and adhesive layer at temperatures less than $20^{\circ} \mathrm{C}$ [4]. Moreover, Aidoo et al. [5], Xie et al. [6], and Charalambidi et al. [7] experimentally verified that for simply supported beams subjected to bending fatigue, failure usually occurs because of fatigue failure of the longitudinal steel reinforcement followed by strip debonding. Furthermore, the fatigue behaviour of RC slabs strengthened with prestressed EB CFRP strips with gradient anchorage at elevated temperatures was investigated by Kotynia et al. [8]. The experiments were performed at the Swiss Federal Laboratories for Material Science and Technology (Empa). In all the tests, failure occurred because of fatigue fracture of the longitudinal steel reinforcement. Strip debonding then occurred as a consequence of the first steel fatigue failure. Lap-shear tests were performed by Bizindavyi et al. [9] at room temperature to assess the influence of load level in the fatigue behaviour of reinforcements. The fatigue crack propagation in the bonded length was verified and described by the authors as follows: (1) During the initial $10-15 \%$ of the specimen life, a crack suddenly appeared in the concrete substrate near the end where the load was applied. (2) In the second stage of approximately $55-75 \%$ of the test life, the crack propagated gradually in mixed mode. This stage ended when the crack changed direction and rapidly propagated to a certain depth of the concrete substrate. (3) Finally, the crack started to propagate faster until a complete separation of the laminate occurred. This last stage comprised approximately $10-15 \%$ of the specimen life.

Another experimental campaign, where double lap-shear tests were performed at room temperature, was performed by Yun et al. [10]. The slips and strip strains during the fatigue test were measured and a significant increase in both variables was observed because of fatigue degradation of the bond interface. The observed post-fatigue monotonic peak load was almost identical to the response of the reference static tests. Finally, the authors concluded that low-level fatigue loading did not cause any significant damage in the overall bond behaviour of these joints.

Ferrier et al. [11] presented limiting values for the allowable fatigue bond shear stresses determined in lapshear tests. High-amplitude/low-cycle fatigue lap-shear tests were presented by Carloni [12] and discussed the sub-critical crack growth during fatigue loading. It was found that the fatigue crack growth occurs at a load which was smaller than the quasi-static critical load and debonding propagated at the epoxy/FRP interface rather than in the epoxy-concrete interface. Mirzazadeh et al. [13] investigated the fatigue behaviour of reinforced concrete beams at low temperatures compared to similar beams tested in fatigue at room temperature. Higher fatigue lives of the low temperature beams than the room temperature beams were found and [13] argued that the reason for this behaviour was the higher strength of the concrete and lower stresses in the tensile reinforcement at low temperature.

Charalambidi et al. [14] gathered international experimental work on the fatigue response of reinforced concrete beams strengthened with fiber reinforced polymers, investigated the critical parameters that affect fatigue performance and proposed an analytical model for the prediction of the fatigue life of FRP strengthened RC beams.

In spite of the existing experimental works where the fatigue behaviour of such elements has been studied, there is a deficiency in the number of fatigue tests at elevated temperatures in similar elements (e.g. as presented in [8]). Experimental measurements on strengthened RC cantilever slabs with a mastic asphalt layer exposed to outside weather conditions in Zurich (Switzerland) have shown that the temperature measured in 
the epoxy layer of EB CFRP strips during the summer period could reach approximately $50^{\circ} \mathrm{C}$ during several weeks $[15,16]$. The solar radiation on the mastic asphalt layer placed on top of these bridge decks induces a significant increase in the epoxy temperature. This means that even in European countries where the maximum temperatures reached during summer are not extremely high, the epoxy temperature could reach values that are very close to the glass transition temperature of the epoxy adhesive. Klamer et al. [17] studied the static behaviour of RC beams strengthened with EB CFRP reinforcements under elevated temperatures and found that the failure loads and failure modes could be influenced significantly by elevated temperatures.

This study investigates the fatigue behaviour of lateral cantilevers of concrete box-girder highway bridges that have been strengthened on the upper side with EB CFRP strips (Fig. 1). The experimental investigation included RC slabs strengthened with prestressed and non-prestressed EB CFRP strips and tested statically at room temperature and under fatigue loading at an elevated temperature of $50^{\circ} \mathrm{C}$. The combination of fatigue and elevated temperature could change the typical fatigue failure mode described by most researchers when these elements are tested at room temperature. This presented investigation was part of a larger test program, where the influence of the asphalt pavement temperature on the short-term static strength and the long-term behaviour of RC slabs strengthened with EB CFRP strips under sustained loading over several years were also examined $[15,18]$. A part of the presented investigation was already presented in the conference [19].

\section{Experiments}

\subsection{Materials, dimensions of the slabs, and test setup}

To study the behaviour of lateral cantilevers of concrete box-girder highway bridges (Fig. 1), large-scale tests on RC elements strengthened with non-prestressed and prestressed EB CFRP strips were performed. In this section, the dimensions of the tested slabs and the setup adopted for such tests are presented. The largescale specimens were designed according to the usual dimensions of a typical cross-section of an RC boxgirder highway bridge in order to assess the behaviour in the transverse direction of such lateral cantilevers strengthened with non-prestressed and prestressed EB CFRP strips. The slabs were $5 \mathrm{~m}$ long, $1 \mathrm{~m}$ wide, and $0.22 \mathrm{~m}$ thick. The longitudinal steel reinforcement consisted of two layers of seven $\phi 12 \mathrm{~mm}$ bars on each side (steel ratio $\rho_{\mathrm{s}}=0.36 \%$ ). The shear reinforcement consisted of $\phi 8 \mathrm{~mm}$ stirrups spaced at $150 \mathrm{~mm}$. The specimens were strengthened on the top side with two EB CFRP strips. The cross-section and reinforcements of the slabs are shown in Fig. 2.

The CFRP strips and epoxy adhesive were provided by S\&P Clever Reinforcement Company (Switzerland). Unidirectional strips were used with a nominal width, thickness, and length of $100 \mathrm{~mm}, 1.2$ $\mathrm{mm}$, and $5000 \mathrm{~mm}$, respectively (FRP ratio $\rho_{\mathrm{f}}=0.11 \%$ ). According to the datasheet [20], the elastic modulus and the tensile strength of the strips were equal or greater than $165 \mathrm{GPa}$ and $2800 \mathrm{MPa}$, respectively. A twocomponent, cold-curing epoxy adhesive, S\&P-220 [21], was used as the bonding material. The axial rigidity ratio $\mathrm{k}_{\mathrm{s}} / \mathrm{k}_{\mathrm{f}}=\mathrm{E}_{\mathrm{s}} \mathrm{A}_{\mathrm{s}} / \mathrm{E}_{\mathrm{f}} \mathrm{A}_{\mathrm{f}}$ (see [14]) of these test beams was 4.1.

The slabs were fabricated using identical concrete mixtures, with a maximum aggregate size equal to 32 $\mathrm{mm}$. The water/cement ratio was 0.50 and the cement (CEM II) content was $325 \mathrm{~kg} / \mathrm{m}^{3}$. The average concrete strengths (compressive and splitting tensile) tested on $150 \times 150 \times 150 \mathrm{~mm}$ cubic specimens at 28 days are given in Table 1. The longitudinal steel reinforcement $(\phi 12 \mathrm{~mm})$ consisted of hot-rolled deformed bars with characteristic yield, ultimate strength and strain at ultimate strength of 595, 670 MPa and 6.9\%, respectively. An elastic modulus of $205 \mathrm{GPa}$ can normally be assumed for such reinforcements.

The load was applied using an oil hydraulic actuator with $150 \mathrm{kN}$ load capacity. A steel beam placed on the top of the concrete surface was used to transfer the load from the actuator to the entire slab width without touching the strips (Fig. 3). To allow free rotation, the slabs were supported by cylindrical steel rollers. The vertical tip displacement at the free edge was measured with linearly variable displacement transducers and/or 
laser sensors. Additionally, several strain gauges were glued on the strips to measure the evolution of the strip strains during the fatigue tests. The distribution of the strain gauges is shown in Fig. 4.

\subsection{Elevated temperature during the fatigue tests}

The fatigue tests were carried out at a constant epoxy temperature of approximately $50^{\circ} \mathrm{C}$. This temperature value was defined in order to represent a reasonable maximum epoxy temperature reached during several days in the summer period in Switzerland. To heat the top surface of the slabs and to maintain this elevated epoxy temperature for several weeks, heating mats, as shown in Fig. 5, were placed on the top surface and were controlled by an electronic device. Due to space limitations (support and loading frame), the strip ends could not be heated (Fig. 3 and Fig. 4).

After placing the heating mats on the top of the strengthened slabs, the insulation material shown in Fig. 6 was added on the top of the mats to maintain the elevated temperature during the tests. Ten type-K thermocouples were distributed along the strips in order to measure and control the epoxy temperature during the tests. The epoxy temperature values measured during the fatigue test on Slab No. 3 are shown in Fig. 7 , with the average epoxy temperature approximately equal to $50^{\circ} \mathrm{C}$. Approximately 3 weeks were required to perform the complete test from the start of the heating until the static failure test after the fatigue test.

\subsection{Application of prestressed CFRP strips}

One of the slabs was strengthened with prestressed CFRP strips with gradient anchorage. This nonmechanical anchorage technique was developed at Empa [22-26] and is characterized by segment-wise adhesive heating, in which the subsequent gradual prestress force decreases symmetrically at both strip ends. A schematic of the strip prestress force release steps for the application of the gradient anchorage method is displayed in Fig. 8. It can be observed that the prestress force in the strip was released in four steps over a total gradient anchorage length of $1200 \mathrm{~mm}$. Each gradient anchorage was divided in four sectors with a length of $300 \mathrm{~mm}$. The initial prestress force in each laminate was equal to $100 \mathrm{kN}$, which corresponds to a strip strain of approximately $5000 \mu \mathrm{m} / \mathrm{m}$. This stress level of approximately $830 \mathrm{MPa}$ in the strips corresponds to approximately $30 \%$ of the ultimate tensile strength. With this configuration, an average shear stress of $0.83 \mathrm{MPa}(100 \mathrm{kN}$ distributed over $1200 \times 100 \mathrm{~mm})$ exists in the gradient anchorage.

The setup used to externally bond and anchor the prestressed EB CFRP strips in one of the slabs in the Empa laboratory is shown in Fig. 9 and Fig. 10. Heating boxes that were developed during a former project [25] were used. During prestressing, the slabs were supported by temporary supports that were used to level the slab and fix the thickness of the epoxy layer. Before the accelerated curing, the strips were prestressed manually using two oil hydraulic jacks and hand pumps. During all the process, the prestress force was measured with two load cells. The accelerated curing process used to anchor the CFRP strips was selected based on the knowledge acquired during previous investigations performed at Empa [22-26]. According to these experimental works, a heating time of 35 min of accelerated curing at approximately $90^{\circ} \mathrm{C}$ epoxy temperature and a subsequent cooling of $15 \mathrm{~min}$ was chosen. The heating of the subsequent gradient sector was started during this additional cooling time with an overlap of $5 \mathrm{~min}$. Then, the initial prestress force was reduced by $25 \mathrm{kN}$ simultaneously on both ends. After sector 2 was cured, again the prestress force was reduced by $25 \mathrm{kN}$ (Fig. 8 and Fig. 12). The same heating and releasing procedures were repeated in sectors 3 and 4 until the prestress force in both strip ends was equal to zero. Approximately $3 \mathrm{~h}$ was required to fully anchor each strip.

In order to control the strip strain during prestressing, and during the fatigue and subsequent static loading tests, strain gauges were glued on the strips before applying the prestress force according to the sketch shown in Fig. 11. One of the strain gauges was glued in the middle of the strips and the others were placed symmetrically at $800 \mathrm{~mm}$ from the middle of the strips. The prestress force in the load cells at the strip ends and the strip strains measured in one of the strengthened slabs are shown in Fig. 12 for strip No. 2, whereas 
strip No. 1 was already applied. According to these measurements, a slight decrease in the strip strains (approximately equal to $2 \%$, from $\approx 5230 \mu \mathrm{m} / \mathrm{m}$ to $\approx 5125 \mu \mathrm{m} / \mathrm{m}$ ) was observed after the complete release of the prestress force owing to the reduction of slab length and epoxy slippage. The four releasing steps are clearly visible in the measurements shown in Fig. 12. Furthermore, in Fig. 12, the measured epoxy temperatures in the gradient length using several type-K thermocouples placed in the middle of each sector are shown.

\section{Results}

\subsection{Reference static tests at room temperature}

In addition to the fatigue tests at elevated temperature, $\mathrm{RC}$ slabs strengthened with non-prestressed and prestressed EB CFRP strips (Slabs No. 1 and No. 2) were also tested at room temperature in order to have a reference value for the static strength. Furthermore, these tests were used to define the load levels for the subsequent fatigue tests at elevated temperature. The load-tip displacement curves measured during the static loading tests at room temperature are shown in Fig. 13. As expected, Fig. 13 demonstrates that the use of prestressed EB CFRP strips, instead of non-prestressed systems, is highly recommended to strengthen existing $\mathrm{RC}$ structures owing to the numerous advantages, namely higher cracking, yielding, and failure loads, lesser number of cracks, and smaller deflections for service load levels (Table 3).

\subsection{Fatigue tests at elevated temperature on RC slabs strengthened with non-prestressed EB CFRP strips}

Two RC slabs strengthened with non-prestressed EB CFRP strips (Slabs No. 3 and No. 4) were tested at elevated temperature under fatigue load. The load levels for these fatigue tests have been defined such that steel fatigue failure is avoided before reaching 2 million load cycles. The main variables fixed for such fatigue tests are summarized in Table 2, with $F$ as the applied load, $\sigma_{s}$ as the calculated tensile stress in the longitudinal reinforcement bars, $\Delta \sigma_{s}$ as the calculated stress oscillation in the longitudinal reinforcement, $\sigma_{f}$ as the calculated strip stresses, $\Delta \sigma_{f}$ as the calculated stress oscillation in the strips, and $R$ as the ratio of the minimum and maximum loads. The calculated values for the stresses summarized in Table 2 were obtained without considering thermal effects. The maximum and minimum load levels for both fatigue tests are shown in Fig. 13, where the load-tip displacement curves measured for the reference static tests at room temperature (Slab No. 1 and No. 2) are also plotted.

The test procedure during the fatigue tests is as follows: First, the heating mats were switched on 3 days before starting the fatigue tests. Afterwards, an approximately constant epoxy temperature of $50^{\circ} \mathrm{C}$ was reached in the epoxy layer (Fig. 7), and several vertical cracks equally distributed along the slab length were observed owing to the thermal expansion of the slabs (Fig. 14 and Fig. 15 to Fig. 17). Then, the first 100 load cycles were performed manually, with intermediate stops after 10 cycles in order to evaluate the fatigue propagation of the existing flexural cracks. After 100 cycles, the fatigue tests were started and the cyclic load was applied with a frequency of approximately $2 \mathrm{~Hz}$.

The evolution of the tip displacements along the 2 million load cycles is shown in Fig. 18 for the maximum and minimum load levels. A gradual increase in the tip displacements was measured owing to the crack propagation (increase in crack lengths and crack widths) and possible slight degradation at the stripepoxy and epoxy-concrete interfaces. The strip strains measured through several strain gauges (Fig. 4) are displayed in Fig. 19, showing a similar variation as the previous tip displacements. After 1 million load cycles, the increase in the experimental measurements (strip strains and displacements) were stabilized and the residual increase in the last 500000 cycles was negligible. 
Both fatigue tests were stopped after specific cycles in order to evaluate the crack propagation and fatigue damage. At these stages, static cycles were performed to quantify the stiffness degradation of the slabs. The load-tip displacement curves from these tests are shown in Fig. 20. According to the measurements, between cycles 1 and 2000 000, the stiffness of Slabs No. 3 and No. 4 decreased by 27\% and 24\%, respectively. After 2 million load cycles, both fatigue tests were stopped without observing any fatigue failure on the longitudinal steel bars. Furthermore, no fatigue damage was observed on the top surface owing to fatigue degradation of the strip-epoxy-concrete joints. The crack patterns of both specimens before and after the fatigue tests at the upper loads are shown in Fig. 15 and Fig. 16.

In order to evaluate the residual load carrying capacity at elevated temperature, both slabs were subjected after 2 million load cycles to a monotonic static loading up to failure. The load-tip displacement curves measured are shown in Fig. 21(a) together with the reference static test at room temperature (Slab No. 1). According to these results, the failure load was approximately $15 \%$ higher in the tests performed at elevated temperature after fatigue loading (Table 3). This significant increase in the failure load could be attributed to the softer behaviour of the epoxy adhesive at elevated temperature and probably owing to the 'post-curing' developed by the adhesive during the fatigue tests $\left(3\right.$ weeks at $\left.50^{\circ} \mathrm{C}\right)$ [27]. Additionally, the load-maximum strip strain curves measured in the section over the central support are shown in Fig. 21(b). Failure always occurred owing to strip debonding with a significant increase in the tip displacements and an extensive crack pattern development (Fig. 22(a) and (b)).

After the experiments, part of the concrete cover located in the area subjected to the maximum bending moment was removed, in order to verify any fatigue or static tensile failure of the longitudinal steel reinforcement. No tensile failure on the longitudinal steel reinforcement was observed.

\subsection{Fatigue test at elevated temperature on an RC slab strengthened with prestressed EB CFRP} strips

One RC slab strengthened with prestressed EB CFRP strips with gradient anchorage (Slab No. 5) was tested at an elevated temperature of $50^{\circ} \mathrm{C}$ under fatigue load (Table 1). Again, the variables selected for this fatigue test, as summarized in Table 2, have been defined such that steel fatigue failure was avoided before reaching 2 million load cycles. The load-tip displacement curves of the reference static tests at room temperature are shown in Fig. 13 together with the fatigue load levels of all the fatigue tests at elevated temperature.

As in the previous fatigue tests, the fatigue test on Slab No. 5 was performed over several weeks. In order to heat the top surface of the slab up to $50^{\circ} \mathrm{C}$, the same heating system consisting of heating mats and a temperature controller was used. The epoxy temperature, which was again measured during the fatigue test through several type-K thermocouples distributed along the strips, had an average value of approximately $50^{\circ} \mathrm{C}$. Three days before starting the fatigue test, the heating mats were switched on. In comparison with the non-prestressed fatigue slabs, less vertical cracks were observed because of thermal expansion of the RC slab. Afterwards, the fatigue test was started and the frequency of the cyclic load was again approximately equal to $2 \mathrm{~Hz}$.

The evolution of the tip displacements in Slab No. 5 is shown in Fig. 23 for the maximum and minimum load levels. The measured strip strains for the same load levels are also shown in Fig. 24. No fatigue damage was observed during the fatigue test. As in Slabs No. 3 and No. 4, the fatigue damage in Slab No. 5 was assessed through several intermediate static cycles shown in Fig. 25, with a stiffness degradation approximately equal to $30 \%$ between cycles 1 and 2000000 . The crack pattern of the specimen before and after the fatigue tests at the upper load is shown in Fig. 17.

After 2 million load cycles, the fatigue test was stopped and the slab was tested at elevated temperature under monotonic static loading up to failure. A comparison of the load-tip displacement curves between this test and the reference static test (Slab No. 2) performed at room temperature in a similar slab without previous 
cyclic load is shown in Fig. 26(a). As in the non-prestressed slabs, the failure load in the test performed at elevated temperature after fatigue loading was slightly higher (Table 3).

The load-strip strain curves measured in the section subjected to maximum bending moment $(\mathrm{x}=0 \mathrm{~mm})$ and in two sections located at $800 \mathrm{~mm}$ from the central support are shown in Fig. 26(b). The maximum strip strain measured at failure was equal to $14454 \mu \mathrm{m} / \mathrm{m}(1.45 \%)$. This value is very close to that of the ultimate strain of the CFRP strips, which is approximately equal to $16500 \mu \mathrm{m} / \mathrm{m}(1.65 \%)$. The failure mode was similar to that observed in the non-prestressed slabs, that is, debonding of the CFRP strips from the concrete (Fig. 22(c)).

\section{Conclusions}

This study deals with the fatigue behaviour at elevated temperature $\left(50^{\circ} \mathrm{C}\right)$ of $\mathrm{RC}$ slabs strengthened with prestressed and non-prestressed EB CFRP strips focusing on the case where these reinforcements are used to strengthen lateral cantilevers of RC box-girder highway bridges. In this study, the combination of elevated temperature and cyclic loads was evaluated using several large-scale slabs, tested as cantilever elements.

The following conclusions can be drawn:

- $\quad$ From the experiments, it was observed that an epoxy temperature of $50^{\circ} \mathrm{C}$ does not negatively influence the fatigue behaviour of the RC elements strengthened with prestressed or non-prestressed EB CFRP strips for the used materials, strip prestress levels and heating layout. After 2 million load cycles, no evidence of steel reinforcement fatigue failure or CFRP strip debonding was observed.

- Because of crack propagation (increase in crack lengths and crack widths) and possible slight degradation at the strip-epoxy and epoxy-concrete interfaces, gradual and slight increases in slab deformations and strip strains were observed in the fatigue tests without significant fatigue damage.

- At the elevated temperature, the residual ultimate loads in the strengthened slabs (with prestressed and non-prestressed strips) were slightly higher than the failure loads in reference static tests at room temperature. This elevated temperature leads to a softer behaviour of the epoxy adhesive because of the lower epoxy stiffness at $50^{\circ} \mathrm{C}$. Furthermore, the 'post-curing' developed by the adhesive during the fatigue tests $\left(3\right.$ weeks at $\left.50^{\circ} \mathrm{C}\right)$ could be related to this improvement. Additionally, the failure mode of such elements was very similar to that observed in the reference tests (that is, failure always occur because of strip debonding).

\section{Acknowledgements}

The financial contribution of the Swiss Road Authorities (FEDRO/ASTRA) within the framework of the project AGB 2012/001 and the Marie Curie Initial Training Network endure (MC-ITN-2013-607851), which provided the scholarship of the first author during this work, are appreciated. The authors also wish to express their acknowledgements to the Empa Structural Engineering Research Laboratory team for their effort for this the experimental investigation, as well as to S\&P Clever Reinforcement AG (Switzerland), for their material contribution. 


\section{References}

1. Kim, Y.J. and P.J. Heffernan, Fatigue behavior of externally strengthened concrete beams with fiber-reinforced polymers: State of the art. Journal of Composites for Construction, 2008. 12(3): p. 246-256.

2. Oudah, F. and R. El-Hacha, Research progress on the fatigue performance of RC beams strengthened in flexure using Fiber Reinforced Polymers. Composites Part B: Engineering, 2013. 47: p. 82-95.

3. Gheorghiu, C., P. Labossière, and J. Proulx, Response of CFRP-strengthened beams under fatigue with different load amplitudes. Construction and Building Materials, 2007. 21(4): p. 756-763.

4. Ferrier, E., D. Bigaud, J.C. Clément, and P. Hamelin, Fatigue-loading effect on RC beams strengthened with externally bonded FRP. Construction and Building Materials, 2011. 25(2): p. 539-546.

5. Aidoo, J., K.A. Harries, and M.F. Petrou, Fatigue behavior of carbon fiber reinforced polymer-strengthened reinforced concrete bridge girders. Journal of Composites for Construction, ASCE, 2004. 8(6): p. 501-509.

6. Xie, J.H., P.Y. Huang, and Y.C. Guo, Fatigue behavior of reinforced concrete beams strengthened with prestressed fiber reinforced polymer. Construction and Building Materials, 2012. 27(1): p. 149-157.

7. Charalambidi, B.G., T.C. Rousakis, and A.I. Karabinis, Fatigue behavior of largescale reinforced concrete beams strengthened in flexure with fiber-reinforced polymer laminates. Journal of Composites for Construction, 2016. 20(5).

8. Kotynia, R., R. Walendziak, I. Stoecklin, and U. Meier, RC slabs strengthened with prestressed and gradually anchored CFRP strips under monotonic and cyclic loading. Journal of Composites for Construction, ASCE, 2011. 15(2): p. 168-180.

9. Bizindavyi, L., K.W. Neale, and M.A. Erki, Experimental investigation of bonded fiber reinforced polymer-concrete joints under cyclic loading. Journal of Composites for Construction, 2003. 7(2): p. 127-134.

10. Yun, Y., Y.F. Wu, and W.C. Tang, Performance of FRP bonding systems under fatigue loading. Engineering Structures, 2008. 30(11): p. 3129-3140.

11. Ferrier, E., D. Bigaud, P. Hamelin, L. Bizindavyi, and K.W. Neale, Fatigue of CFRPs externally bonded to concrete. Materials and Structures/Materiaux et Constructions, 2005. 38(275): p. 39-46.

12. Carloni, C. and K.V. Subramaniam, Investigation of sub-critical fatigue crack growth in FRP/concrete cohesive interface using digital image analysis. Composites Part B: Engineering, 2013. 51: p. 35-43.

13. Mirzazadeh, M.M., M. Noël, and M.F. Green, Fatigue behavior of reinforced concrete beams with temperature differentials at room and low temperature. Journal of Structural Engineering (United States), 2017. 143(7).

14. Charalambidi, B.G., T.C. Rousakis, and A.I. Karabinis, Analysis of the fatigue behavior of reinforced concrete beams strengthened in flexure with fiber reinforced polymer laminates. Composites Part B: Engineering, 2016. 96: p. 69-78.

15. Czaderski, C., J.M. Gallego, and J. Michels, Temperature stability and durability of Externally Bonded CFRP strips in bridge construction, in Forschungsprojekt AGB 2012/001: Arbeitsgruppe Brückenforschung (AGB). Bundesamt für Strassen. 2017: http://www.mobilityplatform.ch/.p. 160.

16. Michels, J., R. Widmann, C. Czaderski, R. Allahvirdizadeh, and M. Motavalli, Glass transition evaluation of commercially available epoxy resins used for civil engineering applications. Composites Part B: Engineering, 2015. 77: p. 484-493. 
17. Klamer, E.L., D.A. Hordijk, and M.C.J. Hermes, The influence of temperature on $R C$ beams strengthened with externally bonded CFRP reinforcement. Heron, 2008. 53(3): p. 157-185.

18. Gallego, J.M., J. Michels, and C. Czaderski, Influence of the asphalt pavement on the short-term static strength and long-term behaviour of $R C$ slabs strengthened with externally bonded CFRP strips. Engineering Structures, 2017. 150: p. 481-496.

19. Gallego, J.M., C. Czaderski, and J. Michels. Experimental behaviour of RC slabs strengthened with EB CFRP strips subjected to fatigue loading at elevated temperature. in ACIC, University of Sheffield, UK, 5 - 7 September 2017. 2017.

20. S\&P. Technical data sheet, $S \& P$ Laminates CFK. S\&P Clever Reinforcement Company AG, CH-6423 Seewen, www.sp-reinforcement.ch 2013.

21. S\&P. Technical data sheet, $S \& P$ Resin 220, epoxy adhesive. S\&P Clever Reinforcement Company AG, CH-6423 Seewen, www.sp-reinforcement.ch 2013.

22. Stöcklin, I. and U. Meier, Strengthening of concrete structures with prestressed and gradually anchored CFRP strips, in FRPRCS-5, July 16-18, 2001. 2001: Cambridge. p. 291-296.

23. Czaderski, C. and M. Motavalli, 40-Year-old full-scale concrete bridge girder strengthened with prestressed CFRP plates anchored using gradient method. Composites Part B: Engineering, 2007. 38(7-8): p. 878-886.

24. Michels, J., C. Czaderski, R. El-Hacha, R. Brönnimann, and M. Motavalli, Temporary bond strength of partly cured epoxy adhesive for anchoring prestressed CFRP strips on concrete. Composite structures, 2012. 94(9): p. 2667-2676.

25. Michels, J., J. Sena-Cruz, C. Czaderski, and M. Motavalli, Structural strengthening with prestressed CFRP strips with gradient anchorage. Journal of Composites for Construction, ASCE, 2013. 17(5): p. 651-661.

26. Michels, J., M. Staśkiewicz, C. Czaderski, R. Kotynia, Y. Harmanci, and M. Motavalli, Prestressed CFRP Strips for Concrete Bridge Girder Retrofitting: Application and Static Loading Test. Journal of Bridge Engineering, ASCE, 2016. 21(5): p. 04016003.

27. Al-Safy, R., R. Al-Mahaidi, and G.P. Simon, Investigation of thermo-mechanical properties of adhesive used for bonding CF fabrics to concrete members using postcuring techniques. Composites Part B: Engineering, 2012. 43(8): p. 2950-2959. 


\section{Nomenclature}

$b_{f}=$ Strip width

$F=$ Applied force

$F_{\max }=$ Maximum applied force

$F_{\min }=$ Minimum applied force

$F_{p}=$ Prestress force in the strip

$f_{c, 28}=$ Concrete compressive strength at 28 days

$f_{c t, 28}=$ Concrete tensile strength at 28 days

$N=$ Number of fatigue cycles

$R=$ Relation between the minimum and maximum load levels

$T_{a}=$ Temperature of the epoxy adhesive

$t_{f}=$ Strip thickness

$\sigma_{f}=$ Tensile stress in the strip

$\sigma_{f \text { max }}=$ Maximum tensile stress in the strip

$\Delta \sigma_{f}=$ Oscillation of the strip stress

$\sigma_{s}=$ Tensile stress in the longitudinal steel reinforcement

$\sigma_{s . \max }=$ Maximum tensile stress in the longitudinal steel reinforcement

$\Delta \sigma_{s}=$ Oscillation of the steel stress

\section{TABLES}

Table 1: Summary of the experimental campaign.

\begin{tabular}{cccccc}
\hline Slab & Load & Strips & $\boldsymbol{T}_{\boldsymbol{a}}\left({ }^{\circ} \mathbf{C}\right)$ & $\boldsymbol{f}_{\boldsymbol{c}, 2 \boldsymbol{s}}(\mathbf{M P a})$ & $\boldsymbol{f}_{\boldsymbol{c t}, 28}(\mathbf{M P a})$ \\
\hline 1 & Static & Non-prestressed & RT & 54.3 & 3.6 \\
2 & Static & Prestressed & RT & 54.0 & 3.5 \\
3 & Fatigue & Non-prestressed & 50 & 56.6 & 3.8 \\
4 & Fatigue & Non-prestressed & 50 & 54.0 & 3.5 \\
5 & Fatigue & Prestressed & 50 & 53.4 & 3.7
\end{tabular}

Table 2: Load levels and calculated tensile stresses for the fatigue tests at elevated temperature.

\begin{tabular}{cccccccc}
\hline Slab & $\boldsymbol{R}$ & $\boldsymbol{F}_{\boldsymbol{m a x}}(\mathbf{k N})$ & $\boldsymbol{F}_{\boldsymbol{m i n}}(\mathbf{k N})$ & $\sigma_{s, \boldsymbol{m a x}}(\mathbf{M P a})$ & $\boldsymbol{\Delta} \boldsymbol{\sigma}_{\boldsymbol{s}}(\mathbf{M P a})$ & $\boldsymbol{\sigma}_{\boldsymbol{f}, \boldsymbol{m a x}}(\mathbf{M P a})$ & $\boldsymbol{\Delta} \sigma_{\boldsymbol{f}}(\mathbf{M P a})$ \\
\hline 3 & 0.50 & 20 & 10 & 260 & 130 & 251 & 126 \\
4 & 0.66 & 30 & 20 & 391 & 131 & 378 & 127 \\
5 & 0.75 & 40 & 30 & 307 & 129 & 1126 & 126
\end{tabular}


Table 3: Measurements during static loading to failure experiments complemented with some calculated values (Slab Nos. 0-2 at room temperatur, Slab Nos. 3-5 at $50^{\circ} \mathrm{C}$ ).

\begin{tabular}{cccccccc}
\hline Slab & $\mathrm{F}_{\mathrm{cr}}$ & $\mathrm{F}_{\mathrm{y}}$ & $\begin{array}{c}\varepsilon_{\mathrm{s}, \mathrm{y}} \\
{[\mu \mathrm{m} / \mathrm{m}]}\end{array}$ & $\begin{array}{c}\varepsilon_{\mathrm{f}, \mathrm{y}} \\
{[\mu \mathrm{m} / \mathrm{m}]}\end{array}$ & $\mathrm{F}_{\max }$ & $\begin{array}{c}\varepsilon_{\mathrm{s}, \max } \\
{[\mu \mathrm{m} / \mathrm{m}]}\end{array}$ & $\begin{array}{c}\varepsilon_{\mathrm{f}, \max } \\
{[\mu \mathrm{m} / \mathrm{m}]}\end{array}$ \\
\hline $0^{\mathrm{a}}$ & $12.1^{\mathrm{a}}$ & $34.1^{\mathrm{a}}$ & $2900^{\mathrm{a}}$ & -- & $39.3^{\mathrm{a}}$ & $25600^{\mathrm{a}}$ & -- \\
1 & 12.1 & $43.2^{\mathrm{b}}$ & 2900 & $4901^{\mathrm{c}}$ & 54.1 & $4750^{\mathrm{d}}$ & $8736^{\mathrm{c}}$ \\
2 & 24.3 & $58.5^{\mathrm{b}}$ & 2900 & $9218^{\mathrm{e}}$ & 74.9 & $5700^{\mathrm{d}}$ & $13052^{\mathrm{e}}$ \\
$3^{\mathrm{f}}$ & & & & 62.4 & & 10100 \\
$4^{\mathrm{f}}$ & & & - & & 62.1 & -- & 9850 \\
$5^{\mathrm{f}}$ & & & & & 78.1 & & 14454
\end{tabular}

$\mathrm{F}_{\mathrm{cr}}=$ Load at first bending cracks, $\mathrm{F}_{\mathrm{y}}=$ Load at start of reinforcement yielding, $\mathrm{F}_{\max }=\overline{\text { maximum Load. }}$

${ }^{a}$ Slab 0 is an unstrengthened beam. Slab No. 0 was not tested, but the values were calculated using cross-sectional analysis for comparison reasons.

${ }^{\mathrm{b}}$ Calculated values from the Load-displacement curve using the graphical method.

${ }^{\mathrm{c}}$ Measured values using the digital image correlation technique.

${ }^{\mathrm{d}}$ Calculated values using cross-sectional analysis.

${ }^{\mathrm{e}}$ Measured maximum values from the strain gauges on the two FRP strips.

${ }^{\mathrm{f}}$ Static loading to failure test at $50^{\circ} \mathrm{C}$ after the 2 million load cycle fatigue test at $50^{\circ} \mathrm{C}$.

Table 4: Measured structural stiffness, tensile stresses in the CFRP strip at initial and final cycle for the fatigue tests at $50^{\circ} \mathrm{C}$.

\begin{tabular}{cccccccc}
\hline Slab & $\begin{array}{c}\mathrm{K}_{1} \\
{[\mathrm{kN} / \mathrm{mm}]}\end{array}$ & $\begin{array}{c}\mathrm{K}_{\text {end }} \\
{[\mathrm{kN} / \mathrm{mm}]}\end{array}$ & $\begin{array}{c}\Delta \mathrm{K} \\
{[\%]}\end{array}$ & $\begin{array}{c}\varepsilon_{\text {fmax }, 1} \\
{[\mu \mathrm{m} / \mathrm{m}]}\end{array}$ & $\begin{array}{c}\varepsilon_{\text {fmax,end }} \\
{[\mu \mathrm{m} / \mathrm{m}]}\end{array}$ & $\begin{array}{c}\varepsilon_{\text {fmin, } 1} \\
{[\mu \mathrm{m} / \mathrm{m}]}\end{array}$ & $\begin{array}{c}\varepsilon_{\text {fmin,end }} \\
{[\mu \mathrm{m} / \mathrm{m}]}\end{array}$ \\
\hline 3 & 1187 & 869 & -27 & 2262 & 2754 & 1667 & 1977 \\
4 & 962 & 731 & -24 & 3238 & 3695 & 2613 & 2878 \\
5 & 1121 & 850 & -30 & 7639 & 8023 & 7159 & 7344
\end{tabular}

Subcript ${ }_{1}$ indicates the values at the first cycle

Subcript end indicates the values at the last cycle

$\mathrm{K}$ is the stiffness and $\Delta \mathrm{K}$ is the $\%$ difference defined as $\left(\mathrm{K}_{1}-\mathrm{K}_{\text {end }}\right) / \mathrm{K}_{1} \cdot 100$ 


\section{FIGURES}

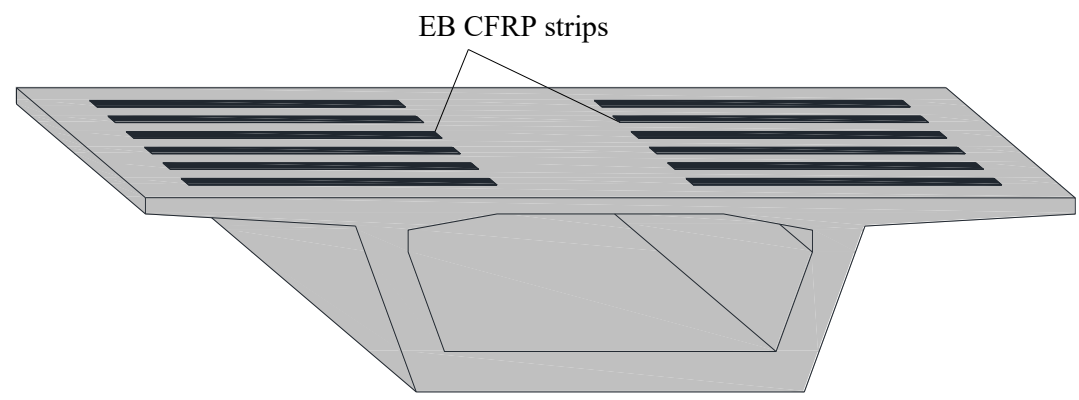

Fig. 1: RC box-girder highway bridge with lateral cantilevers of the top deck slabs, which are strengthened in upper side in transverse direction with EB CFRP strips.
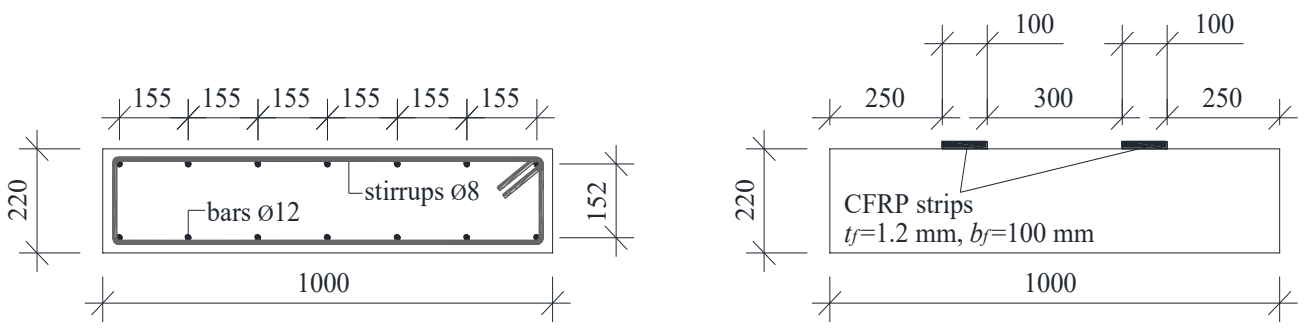

Fig. 2: Cross-sectional dimension and reinforcement of the test slabs.

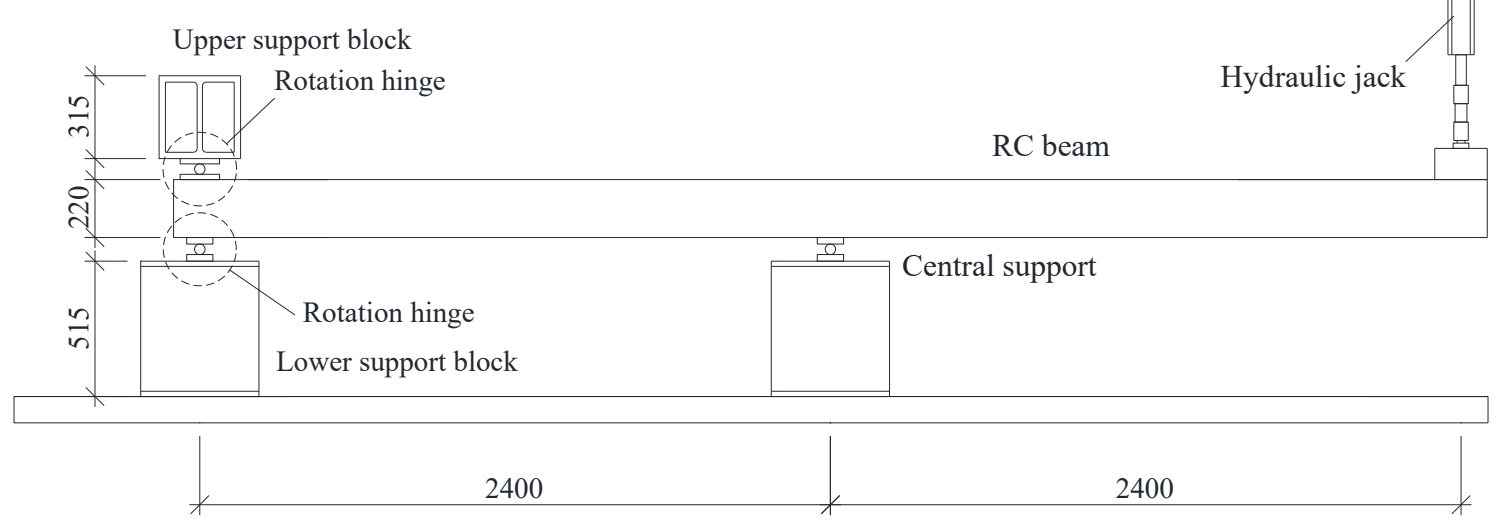

Fig. 3: Test setup for static and fatigue tests (dimensions in $\mathrm{mm}$ ). 


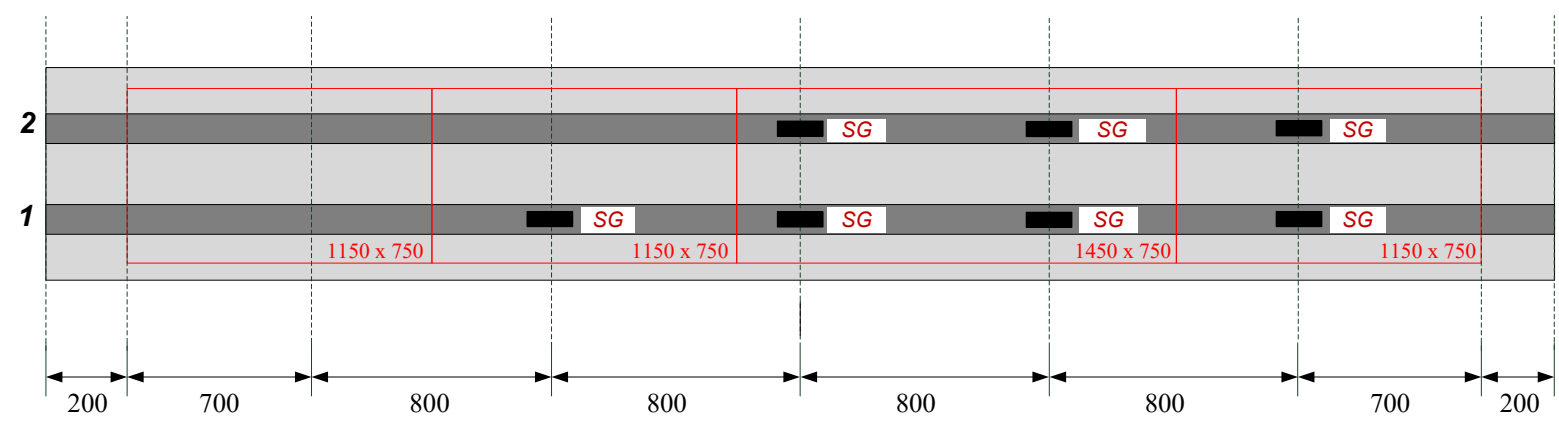

Fig. 4: Distribution of strain gauges (SG) and heating mats (red lines) for the fatigue tests at elevated temperature in RC slabs strengthened with non-prestressed EB CFRP strips (dimensions in $\mathrm{mm}$ ).

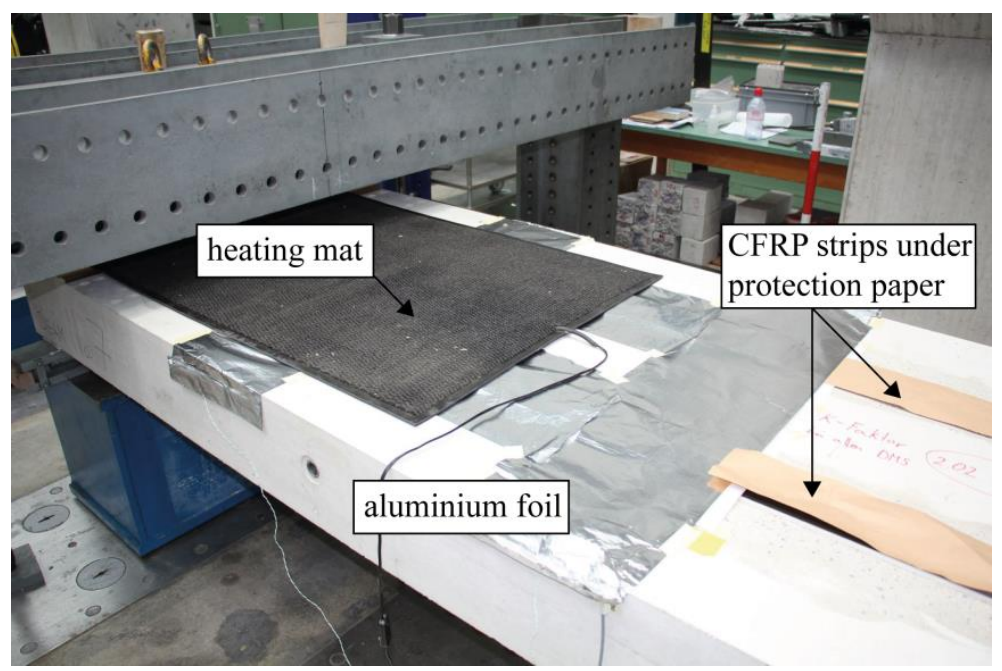

Fig. 5: Detailed view of the setup of one of the slabs tested at elevated temperature: CFRP strips, electrical insulation with protection paper and aluminium foil, and heating mat.

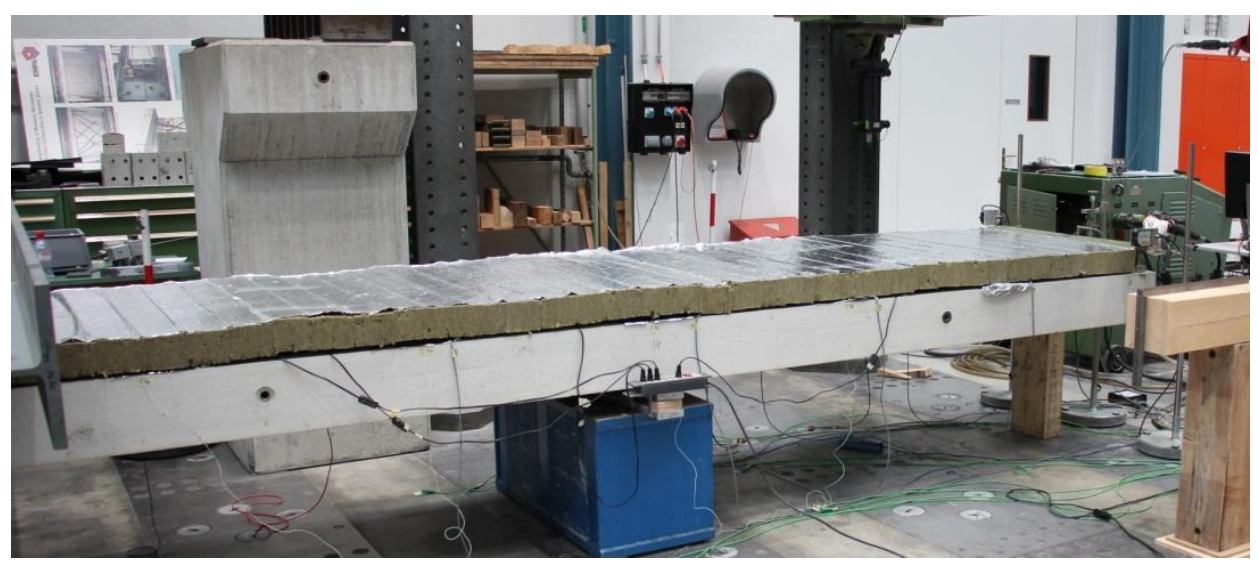

Fig. 6: General view of a test slab after placing the insulation material on top of the heating mats (see Fig. 5). 


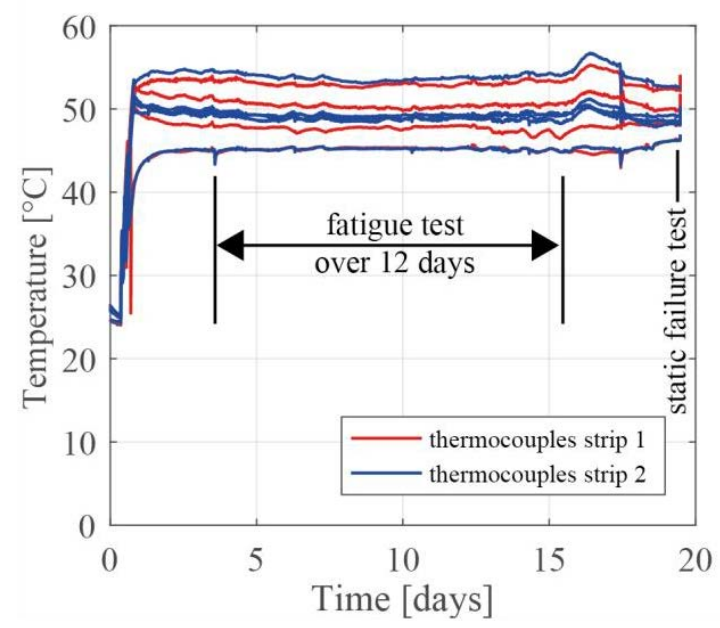

Fig. 7: Epoxy temperature measured during the fatigue and static failure test on Slab No. 3.

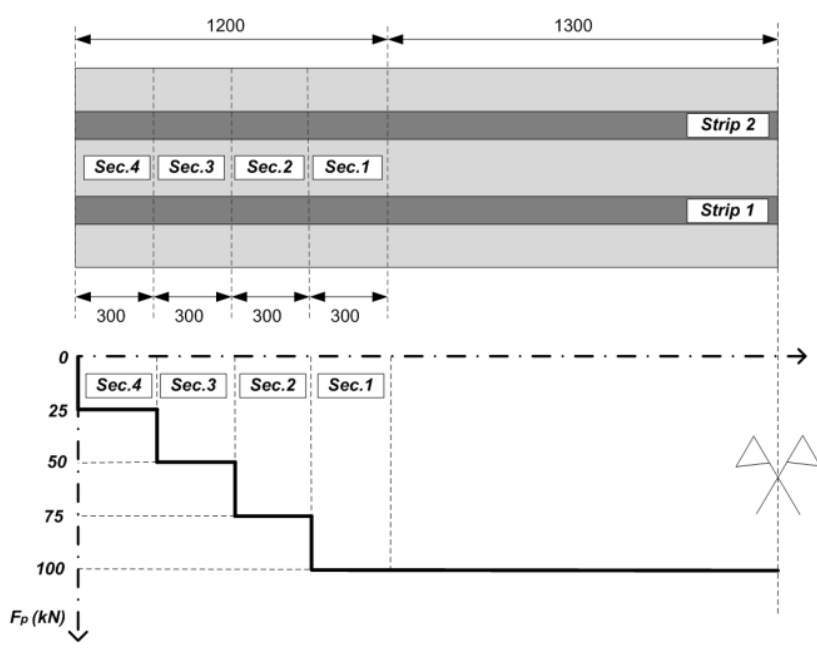

Fig. 8: Distribution of prestress force in the gradient anchorage and strip free length after releasing.

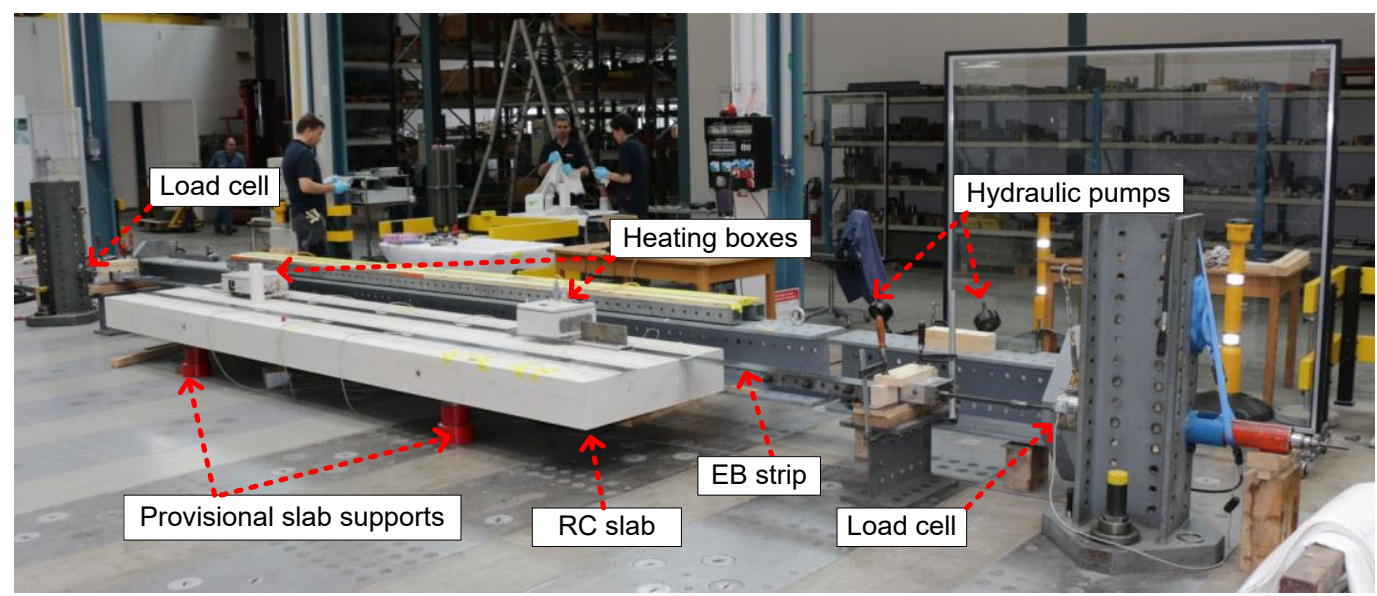

Fig. 9: Laboratory setup used to apply the prestressed EB CFRP strips with gradient anchorage on the test slabs. 


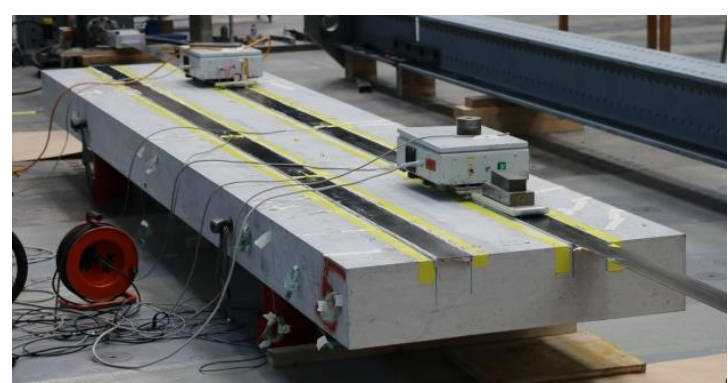

(a)

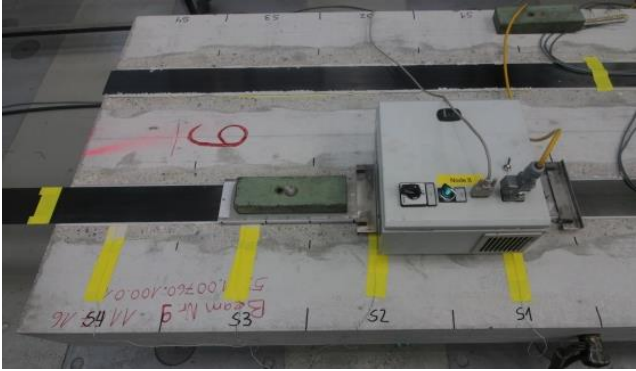

(b)

Fig. 10: Gradient anchorage application to strengthen an RC slab with prestressed strips: (a) General view during prestressing of one strip; (b) Heating box used to perform accelerated curing.

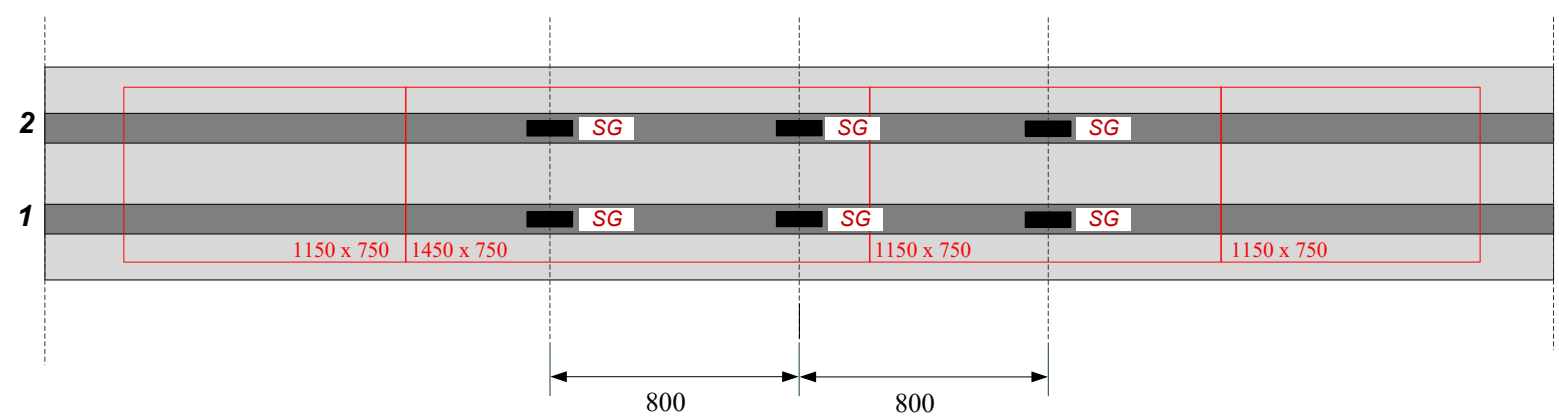

Fig. 11: Distribution of strain gauges and location of heating mats in the RC slab strengthened with prestressed EB CFRP strips (dimensions in $\mathrm{mm}$ ). 

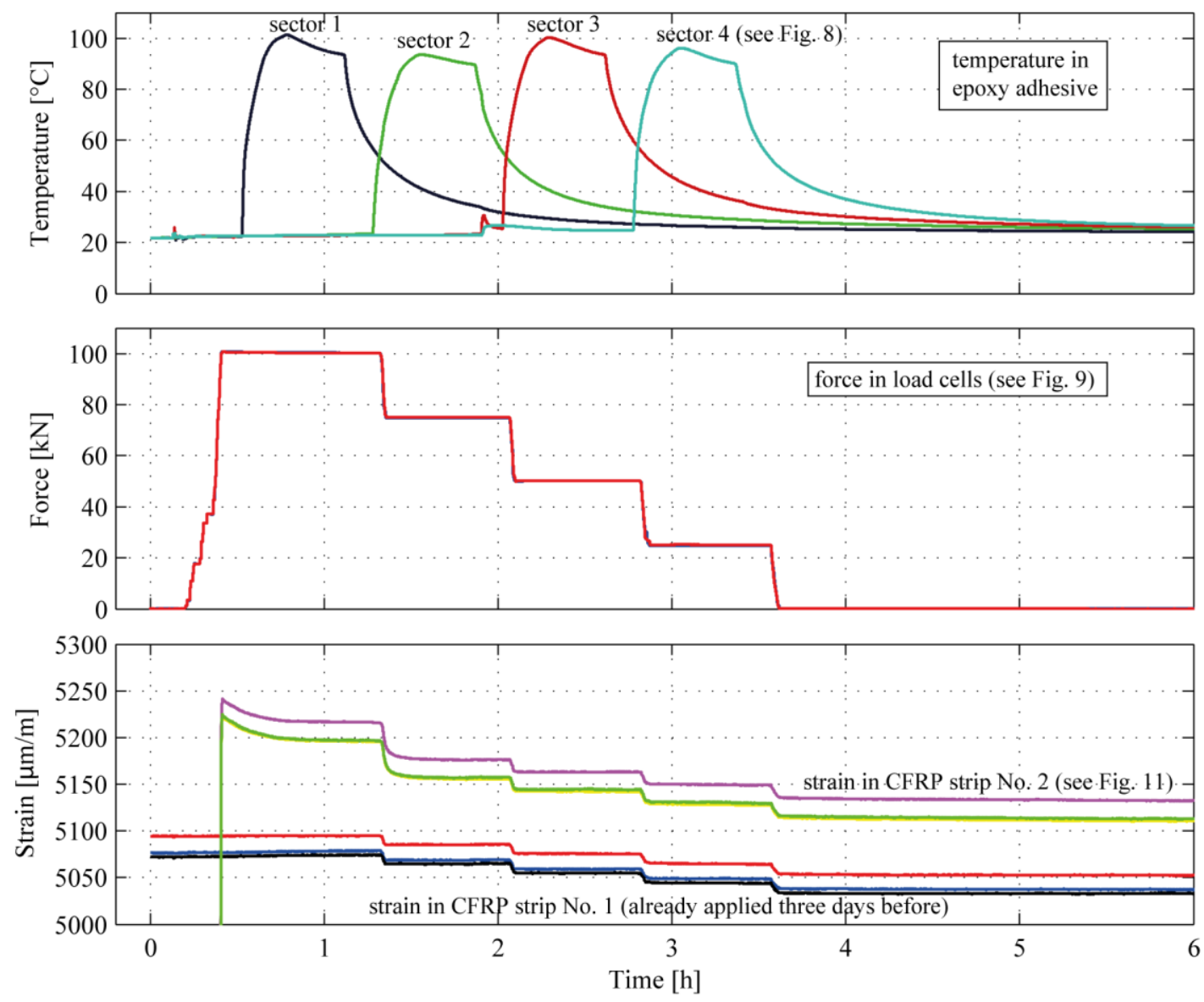

Fig. 12: Epoxy temperature, force at strip end, and strip strain (in the middle) measured during application of gradient anchorage of CFRP strip No. 2 on Slab No. 2.

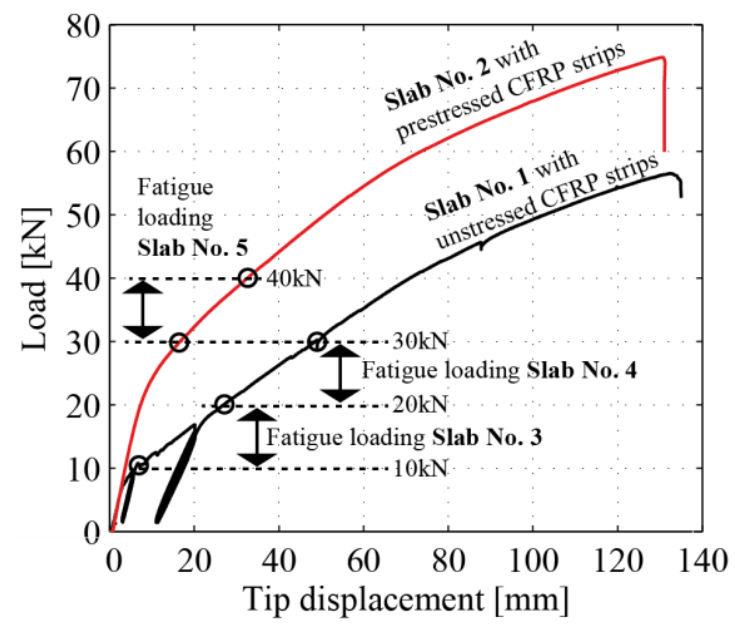

Fig. 13: Load-displacement curves of the monotonic static loading experiments at room temperature on the reference slabs strengthened with non-prestressed and prestressed CFRP strips. The upper and lower loads of the fatigue tests at elevated temperature on Slabs No. 3 to 5 are also displayed. 


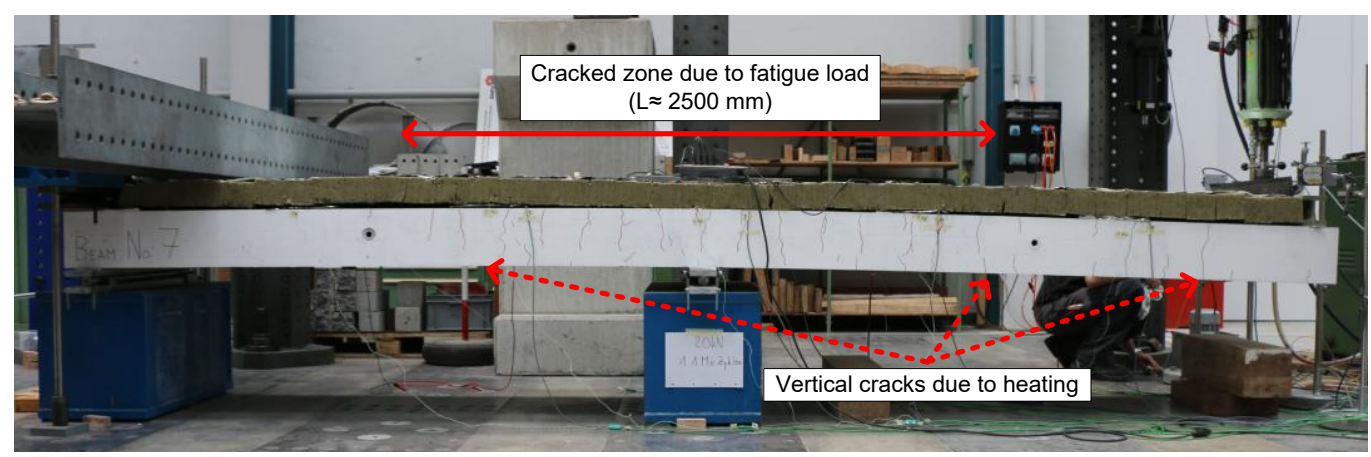

Fig. 14: Crack pattern in Slab No. 7 during the fatigue test.

\section{Beam 3}

After 3 days at $50^{\circ} \mathrm{C}$

Pin

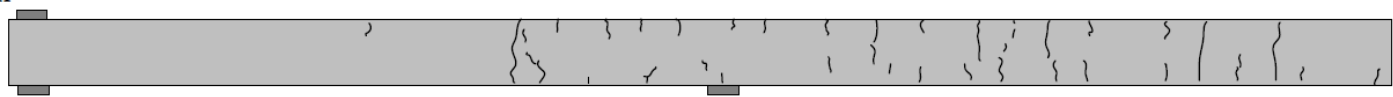

Support

After 3 days at $50^{\circ} \mathrm{C}$ and at $F=20 \mathrm{kN}$

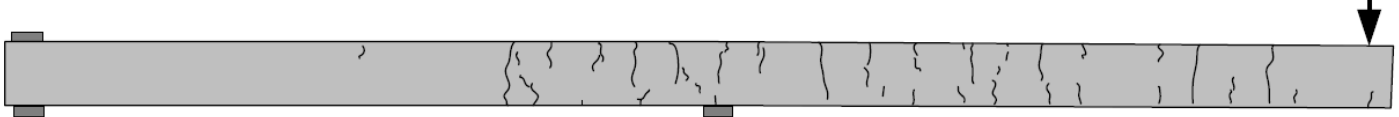

After $2 \cdot 10^{6}$ load cycles at $50^{\circ} \mathrm{C}$ and at $F=20 \mathrm{kN}$

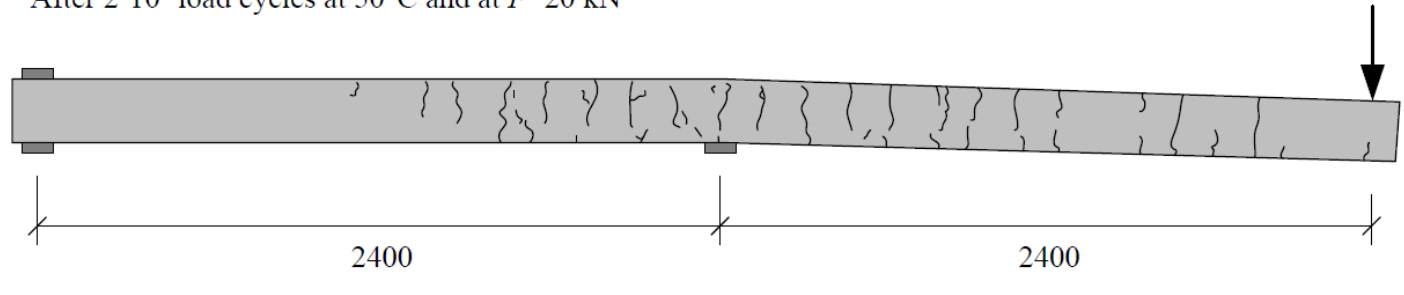

Fig. 15: Crack pattern of cantilever Slab No. 3 after heating, at first loading to upper load of $20 \mathrm{kN}$ and after the fatigue test. 


\section{Beam 4}

After 3 days at $50^{\circ} \mathrm{C}$

Pin

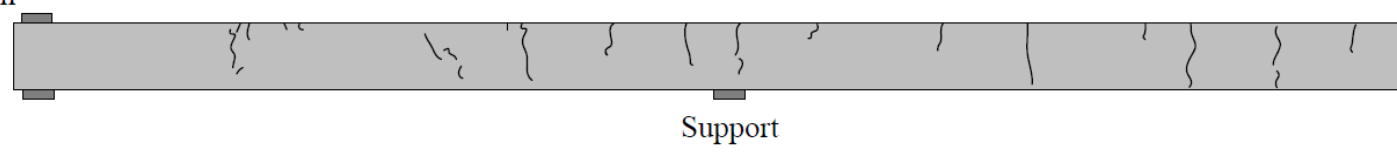

After 3 days at $50^{\circ} \mathrm{C}$ and at $F=30 \mathrm{kN}$

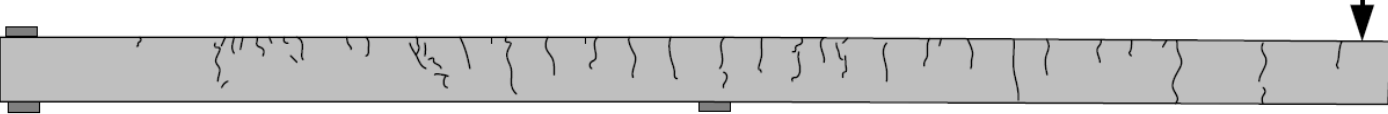

After $2 \cdot 10^{6}$ load cycles at $50^{\circ} \mathrm{C}$ and at $F=30 \mathrm{kN}$

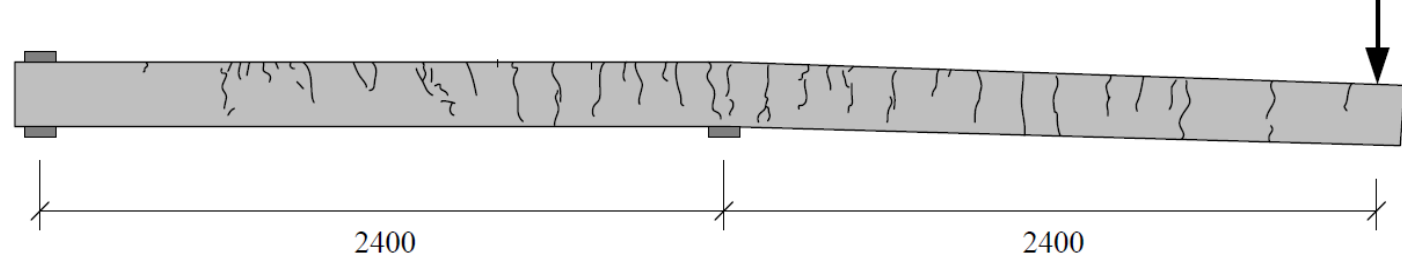

Fig. 16: Crack pattern of cantilever Slab No. 4 after heating, at first loading to upper load of $30 \mathrm{kN}$ and after the fatigue test.

\section{Beam 5}

After 3 days at $50^{\circ} \mathrm{C}$

Pin

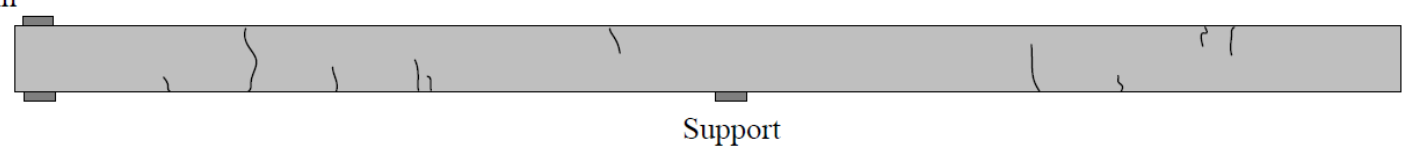

After 3 days at $50^{\circ} \mathrm{C}$ and at $F=40 \mathrm{kN}$

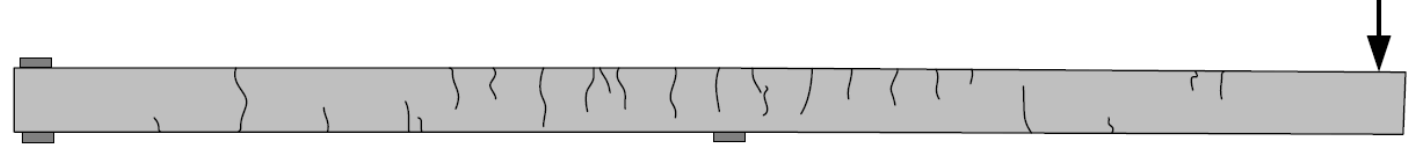

After $2 \cdot 10^{6}$ load cycles at $50^{\circ} \mathrm{C}$ and at $F=40 \mathrm{kN}$

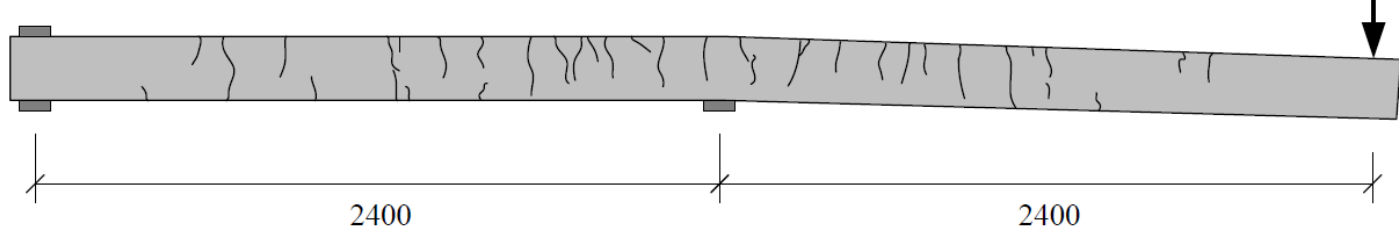

Fig. 17: Crack pattern of cantilever Slab No. 5 after heating, at first loading to upper load of $40 \mathrm{kN}$ and after the fatigue test. 
a)

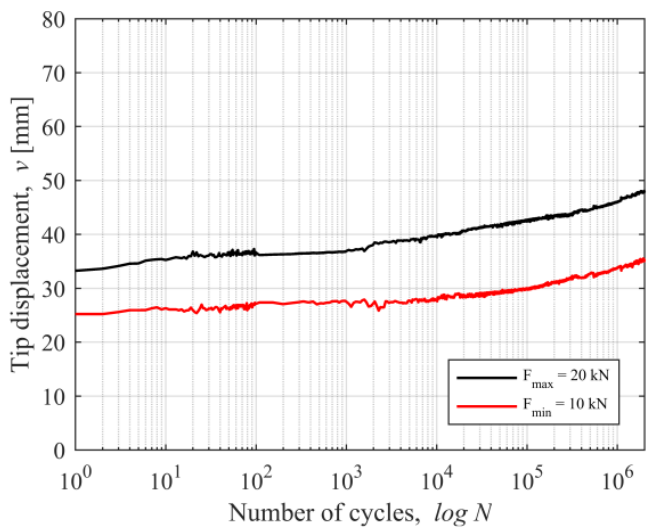

b)

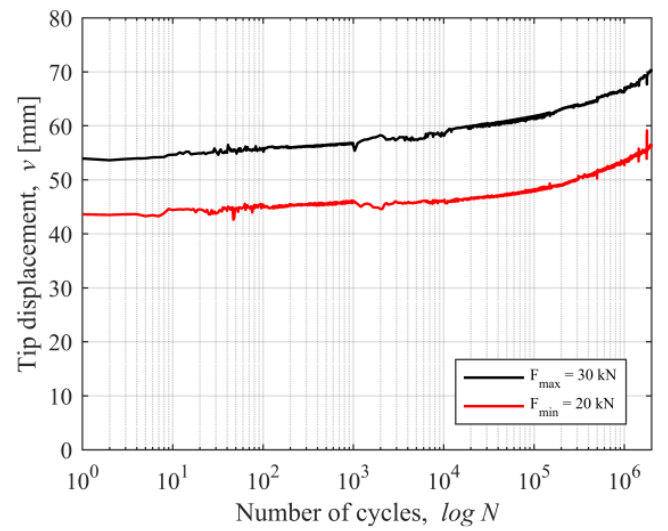

Fig. 18: Evolution of tip displacement during fatigue tests (non-prestressed strips): (a) Slab No. 3; (b) Slab No. 4.

a)

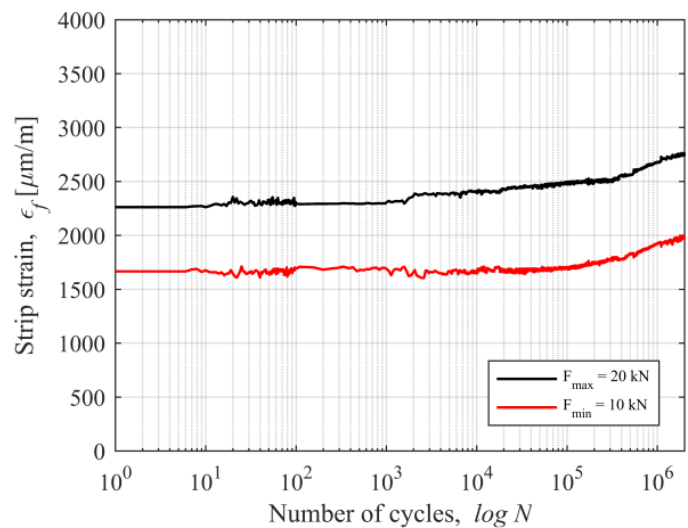

b)

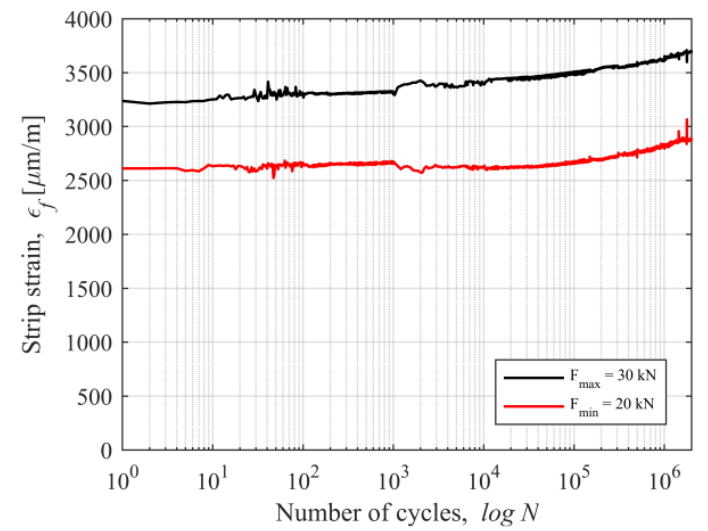

Fig. 19: Evolution of maximum strip strains (section over the central support, see Fig. 4): (a) Slab No. 3; (b) Slab No. 4. 

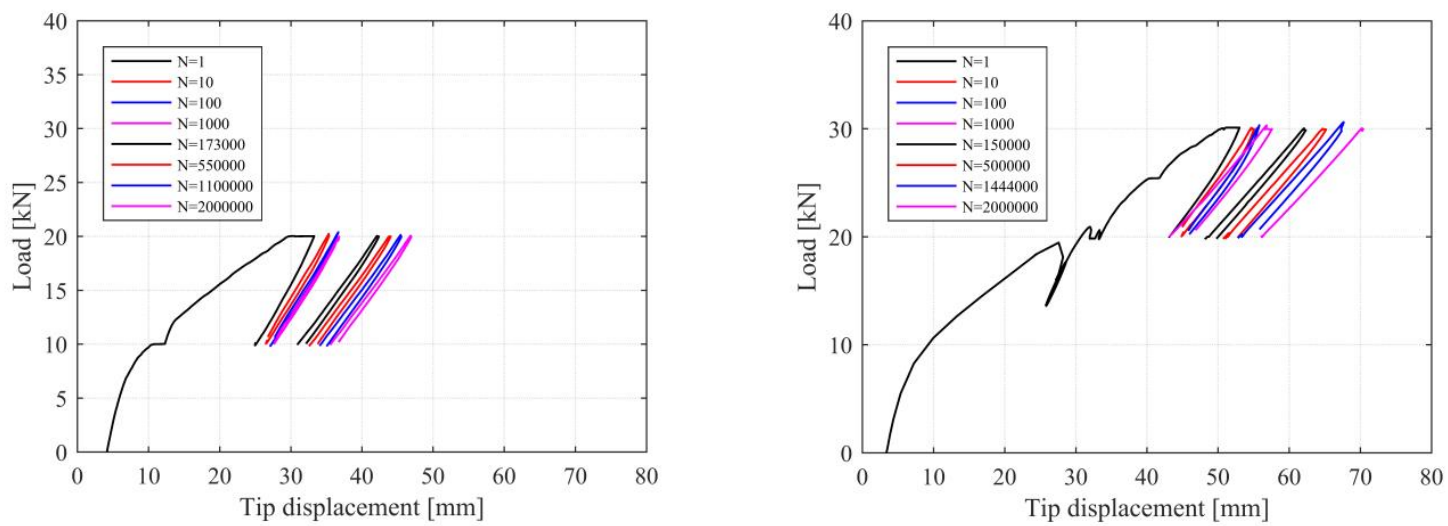

Fig. 20: Intermediate static loading cycles during fatigue tests: (a) Slab No. 3; (b) Slab No. 4.

a)

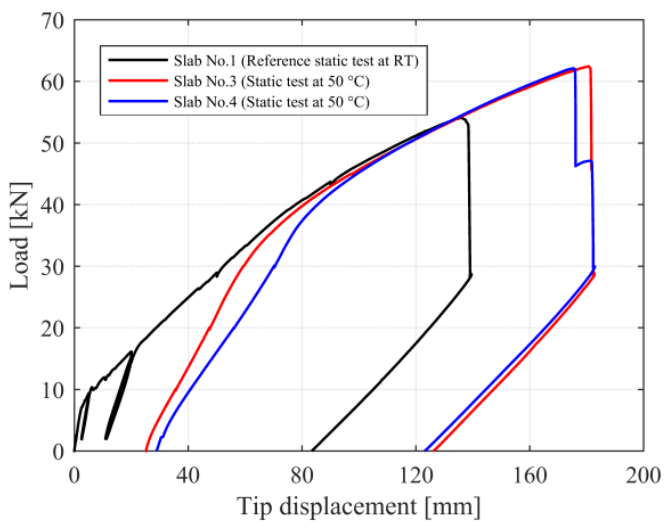

b)

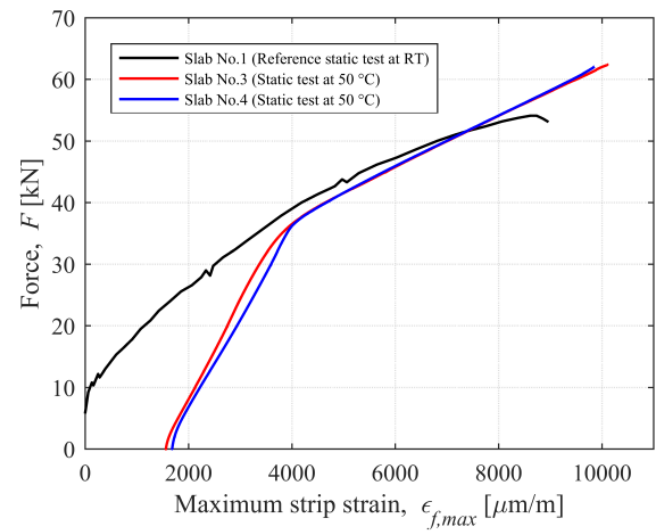

Fig. 21: Static failure tests at elevated temperature after fatigue tests (Slabs No. 3 and No. 4) compared with the reference test at room temperature (Slab No. 1): (a) Load-tip displacement curves; (b) Load-maximum strip strain curves.

(a)

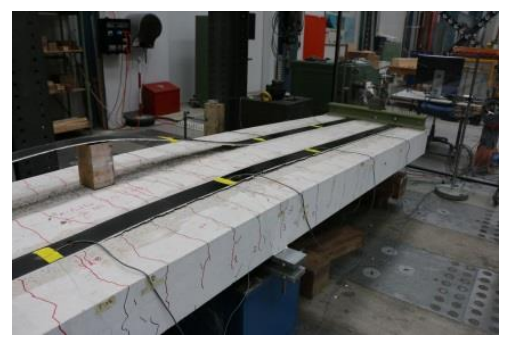

(b)

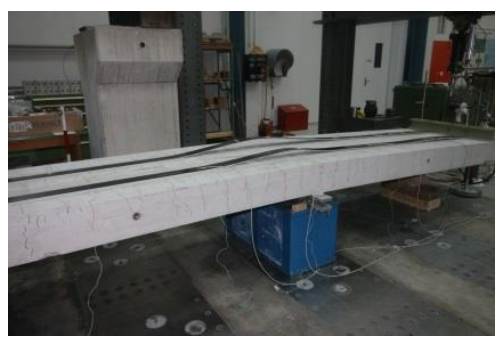

(c)

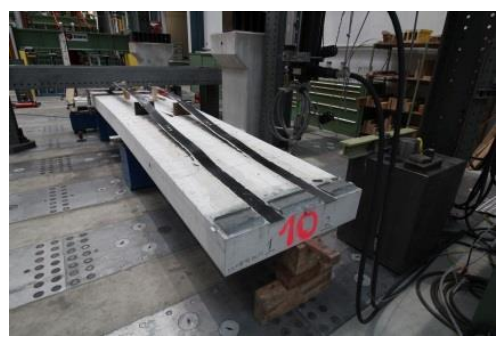

Fig. 22: Failure mode 'debonding of the EB CFRP strips' during the monotonic static loading up to failure at $50^{\circ}$. Photos after removed isolation and heating mats, (a) Slab No. 3; (b) Slab No. 4, (c) Slab No. 5. 


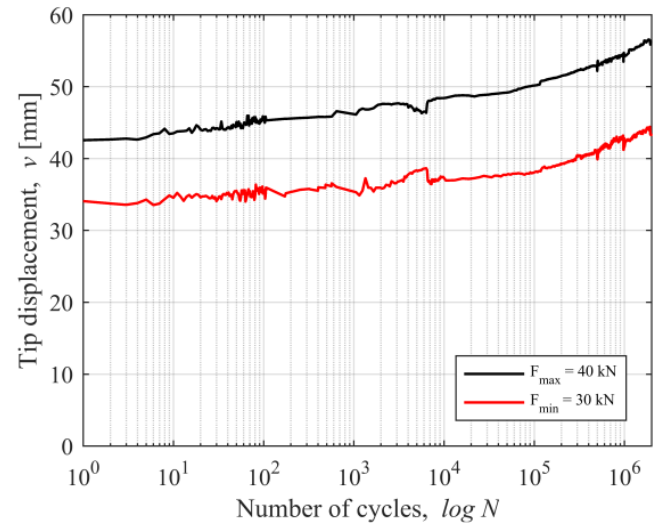

Fig. 23: Evolution of tip displacement during fatigue test of Slab No. 5.

a)

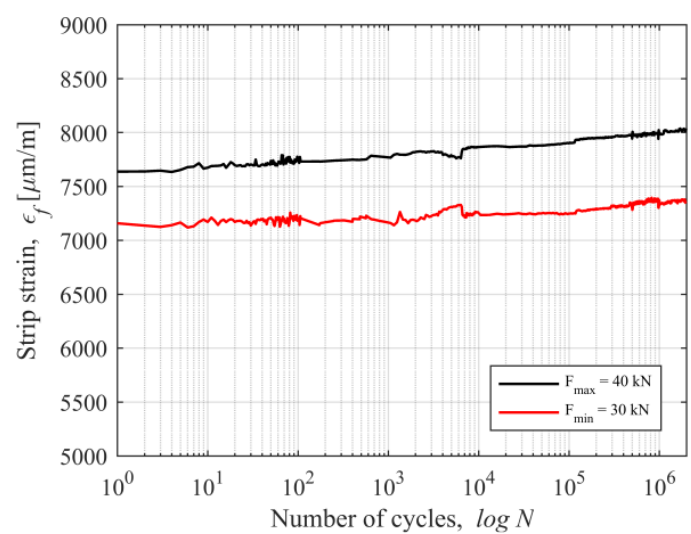

b)

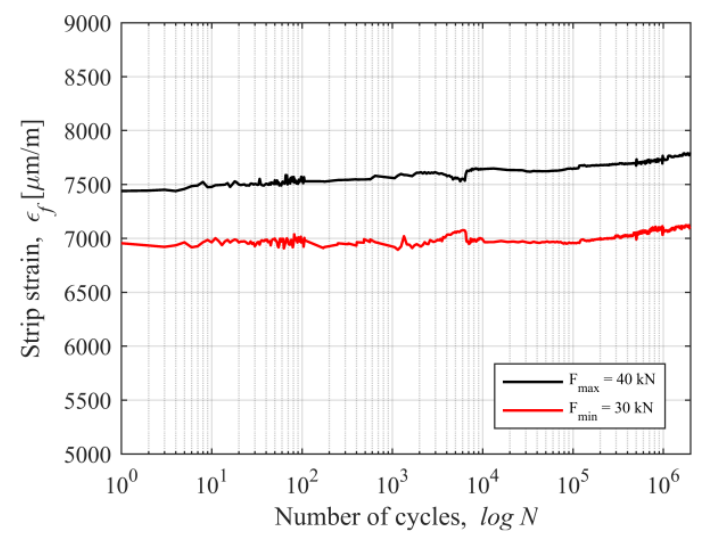

Fig. 24: Evolution of maximum strip strains (section over the central support, see Fig. 4) in Slab No. 5: (a) Strip 1; (b) Strip 2.

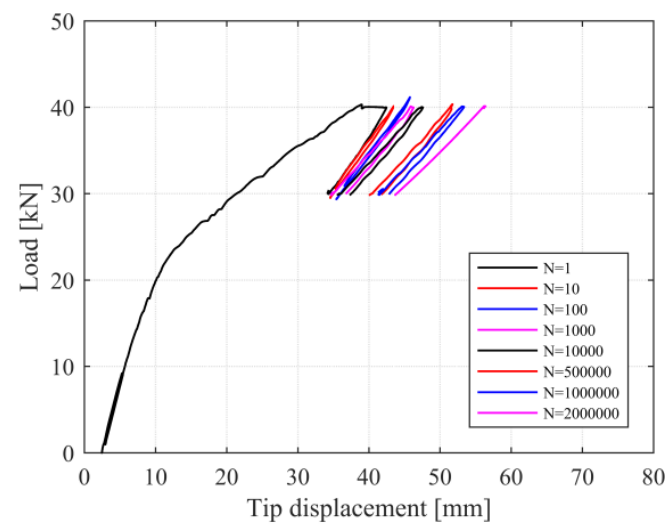

Fig. 25: Intermediate static loading cycles during test on Slab No. 5. 
a)

b)

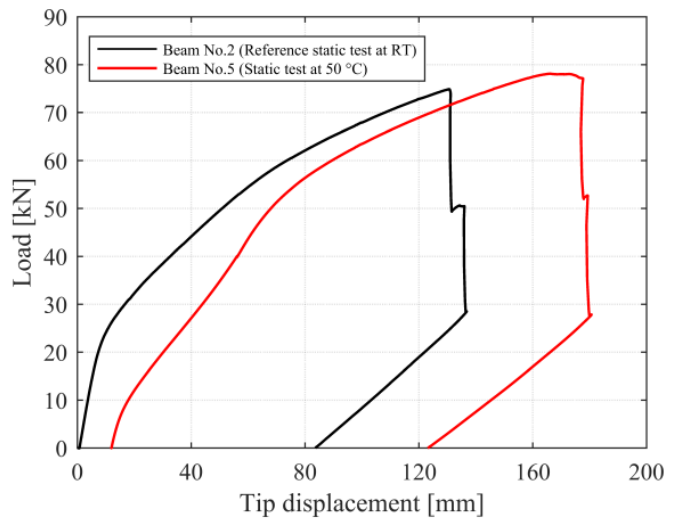

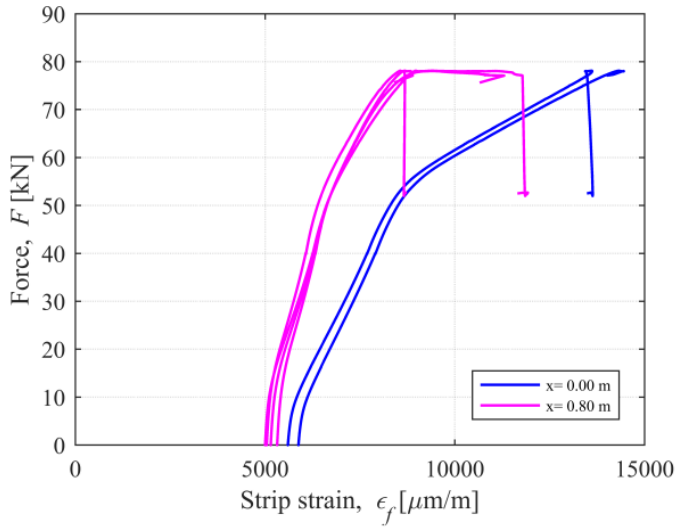

Fig. 26: Static failure test at elevated temperature after fatigue test on the RC slab strengthened with prestressed EB CFRP strips (Slab No. 5) compared with the reference test at room temperature (Slab No. 2): (a) Load-tip displacement curves; (b) Load-strip strain curves for Slab No. 5. 